\title{
The Analysis of Anxiety and Depression in Different Stages of in vitro Fertilization-Embryo Transfer in Couples in China
}

This article was published in the following Dove Press journal: Neuropsychiatric Disease and Treatment

\author{
Yao-Fang Liu' \\ Zheng Fu' \\ Shao-Wei Chen' \\ Xiao-Ping $\mathrm{He}^{2}$ \\ Ling-Ye Fan $\mathbb{D}^{\prime}$
}

'Department of Reproductive Technology, The Affiliated Hospital of Southwest Medical University, Luzhou, 646000, People's Republic of China; ${ }^{2}$ Department of Prosthodontics, The Affiliated Stomatological Hospital of Southwest Medical University, Luzhou, 646000, People's Republic of China
Correspondence: Ling-Ye Fan Department of Reproductive Technology, The Affiliated Hospital of Southwest Medical University, No. 25 of Taiping Street, Jiangyang District, Luzhou, 646000,

People's Republic of China

$\mathrm{Tel} / \mathrm{Fax}+8608303165649$

Email lingyefan_cnsd@।63.com
Background: This study aimed to examine the differences in anxiety and depression between infertile Chinese couples in diverse stages of in vitro fertilization-embryo transfer (IVF-ET) and their relationship with the IVF-ET outcomes.

Methods: From February 2016 to December 2018, a total of 247 couples that were undergoing IVF-ET were randomly selected for this study. On the day they started their treatment (T1), the day human chorionic gonadotropin was administered (T2), and 4 days after the embryo transfer (T3), self-designed questionnaires, the Self-Rating Anxiety Scale, and the Self-Rating Depression Scale were completed to investigate anxiety and depression in different stages.

Results: Age had an effect on the anxiety and depression in women. Male infertility type and the cause of infertility had an effect on the anxiety and depression in men. The incidence of anxiety in women in the T1, T2, and T3 stages was $29.96 \%, 44.94 \%$, and $17.81 \%$, respectively. The anxiety scores of women were $46.14 \pm 8.37,50.83 \pm 8.50$, and $44.09 \pm$ 8.17 , respectively, which were significantly higher than those of men $(\mathrm{p}<0.05)$. The anxiety score in stage T2 was the highest in women, and the depression score of women in stage T1 was the highest. The incidence of anxiety in men in the T1, T2, and T3 stages was $20.65 \%$, $8.50 \%$, and $6.07 \%$, respectively. The incidence of anxiety was not significantly different in diverse stages $(\mathrm{p}>0.05)$, and the same result was obtained for the incidence of depression. The anxiety and depression scores of the infertile couples in different stages were not related to the outcome of IVF-ET.

Conclusion: The incidence of anxiety and depression in infertile couples in diverse stages of IVF-ET is different, especially in women, and the anxiety and depression of infertile couples in the process of IVF-ET may not be related to the outcome of assisted pregnancy. Keywords: anxiety, couple, depression, in vitro fertilization-embryo transfer, outcome

\section{Background}

Infertile couples experience pressure from society, family, and treatment and have a higher risk of negative emotions, such as anxiety and depression. ${ }^{1-3}$ In vitro fertilization-embryo transfer (IVF-ET) is a method in which infertile couples participate to achieve pregnancy. This method has the problems of high cost and uncertain treatment effect, which may cause couples undergoing IVF-ET to experience great pressure. IVF-ET involves different stages, including ovulation induction, ovulation retrieval, and embryo transfer, and patients will face various difficulties in different stages. For example, patients in the stage of ovulation 
induction will worry about the effect of ovulationpromoting drugs, pain, the number of oocytes taken before ovulation, and whether the embryo can be implanted after transplantation. Whether the anxiety and depression of infertile couples in diverse stages of IVF-ET are different and whether they are related to the outcome of assisted pregnancy has been rarely reported. Chinese infertile couples may be affected by the traditional idea of succession, and they are under greater psychological pressure. Therefore, this study analyzed the anxiety, depression, and related factors of infertile couples in different stages of IVF-ET assisted pregnancy, as well as their association with the outcome of assisted pregnancy.

\section{Patients}

Between February 2016 and December 2018, couples undergoing IVF-ET in the Department of Reproductive Technology of the Affiliated Hospital of Southwest Medical University were reviewed on the first day of entering the cycle (T1), the day human chorionic gonadotropin (hCG) was administered (T2), and 4 days after the embryo transfer (T3). Informed consent was obtained from all the patients, and this study protocol was approved by the Ethics Committee of our hospital.

Inclusion criteria: 1) Women aged under 35 years; 2) women with an ovarian reserve function that was normal; 3) women participating in the regular luteal phase long protocol; and 4) women receiving initial IVF cycles.

Exclusion criteria: Patients had major psychological trauma in the past two years.

\section{Methods}

The questionnaire used to determine the couples' basic condition was designed by the team prior to conducting the study. It included age, education level, infertility period, annual family income, and marital relationship.

The symptoms of anxiety were evaluated using the Zung Self-Rating Anxiety Scale (SAS). ${ }^{4}$ The SAS consisted of 20 items, and each item was answered on a 4-point Likert-type scale ranging from "never" to "always". The standard score was the actual score multiplied by 1.25 . The anxiety state was indicated by the SAS standard score $\geq 50$. The degree of anxiety was classified as mild with a score of 50-59 (raw scores 40-47), moderate with a score of 60-69 (raw scores 48-55), and severe with a score of $\geq 70$ (raw scores 56 and over).

The Zung Self-Rating Depression Scale (SDS) was used to assess depressive symptoms. ${ }^{5}$ The SDS is a 20 - item self-report questionnaire, and it was used as a screening tool. Each item was scored from 1 to 4, and the total score was provided by adding the item scores. The standard score was the actual score multiplied by 1.25. The depression state was indicated by the SDS standard score $\geq 50$. The degree of depression was classified as mild with a score of 50-59 (raw scores 40-47), moderate with a score of 60-69 (raw scores 48-55), and severe with a score of $\geq 70$ (raw scores 56 and over). All the participants were informed of the purpose, content, and requirements of the survey to eliminate uncertainties and nervousness. The questionnaires were sent to the couples after they had signed the informed consent form, and all the questionnaires were anonymous. The questionnaire was completed on the first day of entering the cycle (T1), the day of hCG administration (T2), and 4 days after the embryo transfer (T3). All the women and men completed the questionnaire independently. For those with a low education level who could not complete the questionnaire independently, the doctor in charge of the questionnaire described the content of the questionnaire and the patient answered accordingly.

\section{Statistical Analyses}

Continuous variables were expressed as mean \pm standard deviation (normal distribution) or median, while categorical data were expressed as $n(\%)$. All the data were analyzed with SPSS 21.0 (SPSS Inc., Chicago, IL, USA). The statistical methods included a chi-square test/Fisher's exact test, independent sample $t$-test (continuous variables conforming to normal distribution by Shapiro-Wilk test), analysis of variance, and logistic regression analysis. A p-value of less than 0.05 was considered significant.

\section{Results}

\section{The Influencing Factors of Anxiety and Depression in Women Receiving IVF-ET on the First Day of Entering the Cycle}

A total of 247 couples were enrolled in this study (Figure 1). The average age of the women was $29.40 \pm$ 2.98 years, the period of infertility was $3.1 \pm 1.9$ years, and the average age of the men was $31.72 \pm 4.86$ years.

In the 247 women receiving IVF-ET, 29.96\% (74/247) had anxiety on the day of starting the treatment, and the percentage of those with mild, moderate, and severe anxiety was $20.65 \%$ (51/247), $7.69 \%$ (19/247), and 1.62\% (4/247), respectively. Moreover, 15.79\% (39/247) had depression, 


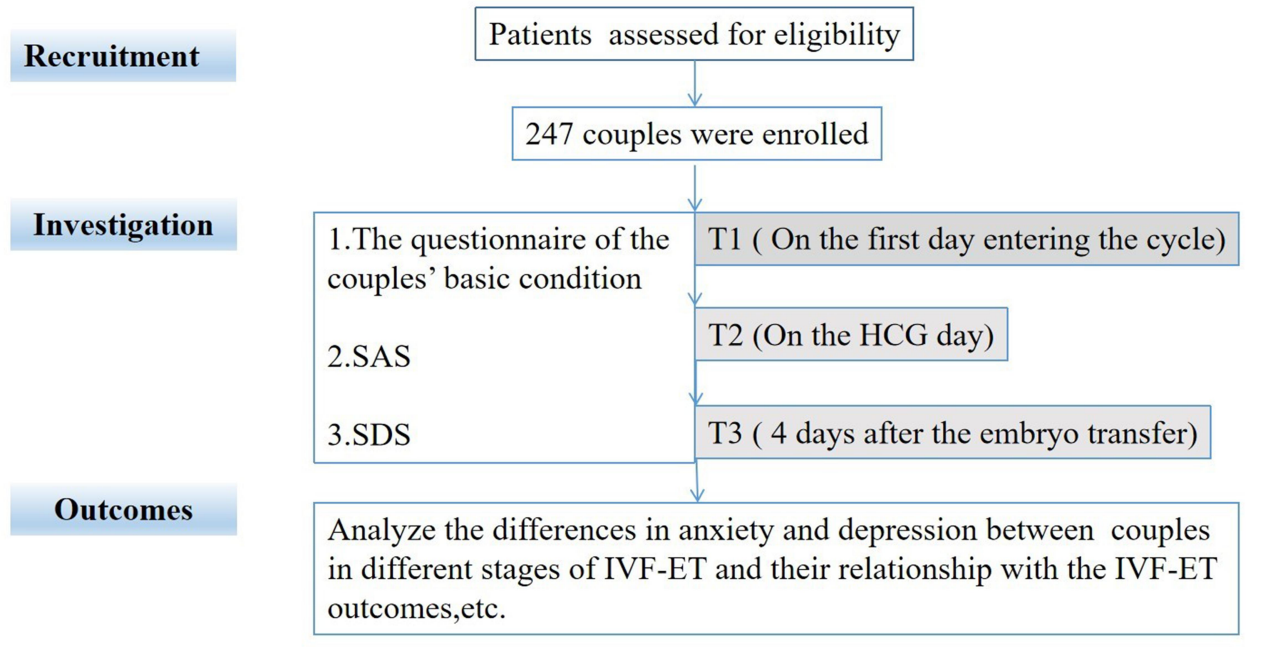

The flow chart

Figure I Flow chart for study design.

and the percentage of those with mild, moderate, and severe depression was $12.55 \%$ (31/247), 2.42\% (6/247), and $0.81 \%$ $(2 / 247)$, respectively. By analyzing the association between anxiety, depression, and their characteristics, we found that there were significant differences in the incidence of anxiety in women in terms of age, infertility period, types of infertility, education level, annual family income, family support, and marital relationship $(\mathrm{p}<0.05)$. Furthermore, the incidence of depression was different according to the patients' age, infertility period, education level, and marital relationship $(\mathrm{p}<0.05)($ Table 1$)$. Logistic regression analysis showed that age, education level, and annual family income had a significant effect on anxiety in women receiving IVF-ET, while age and period of infertility had a significant impact on depression $(p<0.05$, Table 2$)$.

\section{The Influencing Factors of Anxiety and Depression in Men Undergoing IVF-ET}

In the 247 men undergoing IVF-ET, 20.65\% (51/247) had anxiety, with $17.81 \%$ (44/247) having mild anxiety, and $2.83 \%$ (7/247) having moderate anxiety. Moreover, $13.77 \%(34 / 247)$ had depression, and in all cases, this was mild depression. The incidence of anxiety was significantly different in terms of the different types of infertility, causes of infertility, and family support $(\mathrm{p}<0.05)$, and the incidence of depression was different in terms of different types of infertility, causes of infertility, and annual family income $(\mathrm{p}<0.05)$ (Table 3$)$.

\section{The Differences in the Incidence and Scores of Anxiety and Depression in Diverse Stages of IVF-ET Between Women and Men}

The incidence of anxiety was $29.96 \%, 44.94 \%$, and $17.81 \%$ in the $\mathrm{T} 1, \mathrm{~T} 2$, and $\mathrm{T} 3$ stages, respectively. The anxiety scores were $46.14 \pm 8.37,50.83 \pm 8.50$, and $44.09 \pm 8.17$, respectively. The incidence and scores of anxiety in these three stages were significantly higher in women than in men $(p<0.05)$. The incidence of depression in women receiving IVF-ET was $15.79 \%, 9.31 \%$, and $6.88 \%$ in the three stages, respectively. There was no significant difference in the incidence and scores of depression between women and men (Figures 2 and 3 ). The anxiety score in the T2 stage was the highest in women, and it was significantly higher than that in the T1 and T3 stages. The depression score of women in the T1 stage was also the highest, and it was significantly higher than in the T2 and T3 stages. In men, the incidence of anxiety in the T1, T2, and T3 stages was $20.65 \%, 8.50 \%$, and $6.07 \%$, respectively, while the incidence of depression was $13.77 \%, 8.91 \%$, and $8.91 \%$, respectively. The incidence of anxiety and depression was not significantly different in diverse stages. There was no significant difference in male anxiety and depression scores in the different stages (Figure 4). 
Table I Univariate Analysis of Anxiety and Depression-Related Factors in IVF-ET Women

\begin{tabular}{|c|c|c|c|c|c|c|c|c|}
\hline \multirow[t]{2}{*}{ Related Factors } & \multicolumn{2}{|c|}{ Anxiety $(n, \%)$} & \multirow[t]{2}{*}{$X^{2}$} & \multirow[t]{2}{*}{$\mathbf{P}$} & \multicolumn{2}{|c|}{ Depression (n,\%) } & \multirow[t]{2}{*}{$X^{2}$} & \multirow[t]{2}{*}{$\mathbf{P}$} \\
\hline & Yes & No & & & Yes & No & & \\
\hline Age(y) & & & 68.32 & 0.00 & & & 16.97 & 0.00 \\
\hline$<30(126)$ & $8(6.30)$ & $118(93.70)$ & & & $9(7.10)$ & $117(92.90)$ & & \\
\hline$\geq 30(|2|)$ & $66(54.50)$ & $55(45.50)$ & & & $30(27.00)$ & $81(73.00)$ & & \\
\hline Infertility period(y) & & & II.47 & 0.00 & & & 28.19 & 0.00 \\
\hline$<5(134)$ & $28(20.90)$ & $106(79.10)$ & & & $6(4.50)$ & $128(95.50)$ & & \\
\hline$\geq 5(113)$ & $46(40.70)$ & $67(59.30)$ & & & $33(29.20)$ & $80(70.80)$ & & \\
\hline Infertility type & & & 4.74 & 0.00 & & & 0.07 & 0.47 \\
\hline Primary infertility(106) & $24(22.60)$ & $82(77.40)$ & & & $16(15.10)$ & $90(84.90)$ & & \\
\hline Secondary infertility (I4I) & $50(35.5)$ & $91(64.5)$ & & & $23(16.30)$ & II8(83.70) & & \\
\hline Cause of infertility & & & 6.47 & 0.09 & & & 2.30 & 0.51 \\
\hline Female(II8) & $44(37.30)$ & $74(62.70)$ & & & $18(\mid 5.30)$ & $100(84.70)$ & & \\
\hline Male (47) & $13(27.70)$ & $34(72.30)$ & & & $10(21.30)$ & $37(78.70)$ & & \\
\hline Both sides $(62)$ & $13(21.00)$ & $49(79.00)$ & & & $7(11.30)$ & $55(88.70)$ & & \\
\hline Unknown reason(20) & $4(20.00)$ & $16(80.00)$ & & & $4(20.00)$ & $16(80.00)$ & & \\
\hline Educational level & & & 25.62 & 0.00 & & & 4.31 & 0.03 \\
\hline High school or below(140) & $60(42.90)$ & $80(57.10)$ & & & $28(20.00)$ & $112(80.00)$ & & \\
\hline College degree and above (107) & $14(13.10)$ & $93(86.90)$ & & & $\mathrm{II}(10.30)$ & $96(89.70)$ & & \\
\hline Annual family income & & & 23.26 & 0.00 & & & 2.16 & 0.10 \\
\hline$<40,000$ yuan $(119)$ & $53(44.50)$ & $66(55.50)$ & & & $23(19.30)$ & $96(80.70)$ & & \\
\hline$\geq 40,000$ yuan $(128)$ & $21(16.4)$ & $107(83.60)$ & & & $16(12.50)$ & $1 \mid 2(87.50)$ & & \\
\hline Family support & & & 9.16 & 0.00 & & & 0.39 & 0.33 \\
\hline Supported(199) & $5 I(25.60)$ & I48(74.40) & & & $30(15.10)$ & $169(84.90)$ & & \\
\hline Partially supported(48) & $23(47.90)$ & $25(52.10)$ & & & $9(18.80)$ & $39(81.30)$ & & \\
\hline Marital relationship & & & 4.77 & 0.02 & & & 4.36 & 0.03 \\
\hline Harmony(168) & $43(25.60)$ & $125(74.40)$ & & & $21(12.40)$ & $147(87.60)$ & & \\
\hline Not bad(79) & $31(39.20)$ & $48(60.80)$ & & & $18(22.80)$ & $61(77.20)$ & & \\
\hline
\end{tabular}

\section{The Association Between Anxiety and} Depression in Women/Men and IVF-ET

\section{Outcomes}

In this study, 117 cases of pregnancy and 130 cases of nonpregnancy were examined. We found that there was no significant difference in anxiety and depression scores between the pregnancy and non-pregnancy groups (Figure 5).

\section{Discussion}

In this study, we found that the incidence of anxiety and depression in infertile couples undergoing IVF-ET is related to many factors, such as types of infertility, and family income. We also found that the incidence and scores of anxiety and depression are different in diverse stages of IVF-
ET, especially in women. The anxiety score in stage T2 was the highest in women, and the depression score of women in stage T1 was the highest.

Infertile couples in China frequently experience pressure from traditional ideals, families, individual aspects, and other aspects, which leads to anxiety, depression, and other psychological disorders. ${ }^{6,7}$ This study found that the incidence of anxiety and depression on the first day of entering the IVF-ET cycle in infertile women was $29.96 \%$ and $15.79 \%$, respectively, which was similar to the findings reported by Huang et al. ${ }^{8,9}$ Logistic regression analysis indicated that the incidence of anxiety in women was related to age, education level, and annual family income, and the incidence of depression was related to age and infertility period, which was consistent with the report of $\mathrm{Xu}$ and other reports. ${ }^{10-13}$ The incidence of anxiety and 
Table 2 Logistic Regression Analysis of Influencing Factors of Anxiety and Depression in Women with IVF-ET

\begin{tabular}{|l|l|l|l|l|l|l|}
\hline Variables & Regression Coefficient & Standard Error & $\begin{array}{l}\text { Standard Regression } \\
\text { Coefficient }\end{array}$ & P & OR/Exp(B) & 95\% CI \\
\hline $\begin{array}{l}\text { Anxiety } \\
\text { Constant } \\
\text { Age }\end{array}$ & $\begin{array}{l}-24.173 \\
0.733\end{array}$ & $\begin{array}{l}3.859 \\
0.115\end{array}$ & $\begin{array}{l}39.234 \\
40.631\end{array}$ & 0.000 & \\
\hline Educational level & -1.621 & 0.461 & 12.348 & 0.000 & 2.081 & $1.661 \sim 2.607$ \\
\hline Annual family income & -1.485 & 0.453 & 10.760 & 0.000 & 0.198 & $0.080 \sim 0.488$ \\
\hline $\begin{array}{l}\text { Depression } \\
\text { Constant } \\
\text { Age }\end{array}$ & -12.361 & 2.713 & 0.079 & 0.001 & 0.227 & $0.093 \sim 0.550$ \\
\hline \begin{tabular}{l} 
Infertility period \\
\hline
\end{tabular} & 0.231 & 0.046 & 0.483 & 17.961 & 0.000 & 0.000 \\
1.260 & 0.004 & $1.078 \sim 1.472$ \\
\hline
\end{tabular}

Table 3 Univariate Analysis of Anxiety and Depression-Related Factors in Men with IVF-ET

\begin{tabular}{|c|c|c|c|c|c|c|c|c|}
\hline \multirow[t]{2}{*}{ Related Factors } & \multicolumn{2}{|c|}{ Anxiety (n,\%) } & \multirow[t]{2}{*}{$X^{2}$} & \multirow[t]{2}{*}{$\mathbf{P}$} & \multicolumn{2}{|c|}{ Depression (n,\%) } & \multirow[t]{2}{*}{$X^{2}$} & \multirow[t]{2}{*}{$\mathbf{P}$} \\
\hline & Yes & No & & & Yes & No & & \\
\hline $\begin{array}{l}\text { Age }(y) \\
\qquad 30(83) \\
\quad \geq 30(164)\end{array}$ & $\begin{array}{l}15(18.10) \\
36(22.00)\end{array}$ & $\begin{array}{l}68(81.90) \\
128(78.00)\end{array}$ & 0.51 & 0.30 & $\begin{array}{l}10(12.00) \\
24(14.60)\end{array}$ & $\begin{array}{l}73(88.00) \\
140(85.40)\end{array}$ & 0.31 & 0.36 \\
\hline $\begin{array}{l}\text { Infertility period }(y) \\
\qquad 5(138) \\
\quad \geq 5(109)\end{array}$ & $\begin{array}{l}23(16.70) \\
28(25.70)\end{array}$ & $\begin{array}{l}1 \mathrm{I} 5(83.30) \\
8 \mathrm{I}(74.30)\end{array}$ & 3.03 & 0.06 & $\begin{array}{l}15(10.90) \\
19(17.40)\end{array}$ & $\begin{array}{l}123(89.10) \\
90(82.60)\end{array}$ & 2.21 & 0.10 \\
\hline $\begin{array}{l}\text { Infertility type } \\
\text { Primary infertility(69) } \\
\text { Secondary infertility(178) }\end{array}$ & $\begin{array}{l}30(43.50) \\
21(11.80)\end{array}$ & $\begin{array}{l}39(56.50) \\
157(88.20)\end{array}$ & 30.46 & 0.00 & $\begin{array}{l}20(29.00) \\
14(7.90)\end{array}$ & $\begin{array}{l}49(71.00) \\
164(92.10)\end{array}$ & 18.69 & 0.00 \\
\hline $\begin{array}{l}\text { Cause of infertility } \\
\text { Female(1 } 18) \\
\text { Male (47) } \\
\text { Both sides(62) } \\
\text { Unknown reason(20) }\end{array}$ & $\begin{array}{l}17(14.40) \\
23(48.90) \\
9(14.50) \\
2(10.00)\end{array}$ & $\begin{array}{l}101(85.60) \\
24(51.20) \\
53(85.50) \\
18(90.00)\end{array}$ & 28.57 & 0.00 & $\begin{array}{l}10(8.50) \\
16(34.00) \\
5(8.10) \\
3(15.00)\end{array}$ & $\begin{array}{l}108(91.50) \\
31(66.00) \\
57(91.90) \\
17(85.00)\end{array}$ & 20.79 & 0.00 \\
\hline $\begin{array}{l}\text { Educational level } \\
\text { High school or below(16I) } \\
\text { College degree and above(86) }\end{array}$ & $\begin{array}{l}34(21.10) \\
17(19.80)\end{array}$ & $\begin{array}{l}127(78.90) \\
69(80.20)\end{array}$ & 0.06 & 0.47 & $\begin{array}{l}23(I 4.30) \\
\mathrm{II}(I 2.80)\end{array}$ & $\begin{array}{l}138(85.70) \\
75(87.20)\end{array}$ & 0.11 & 0.45 \\
\hline $\begin{array}{l}\text { Annual family income } \\
<40,000 \text { yuan }(119) \\
\geq 40,000 \text { yuan }(128)\end{array}$ & $\begin{array}{l}28(23.50) \\
23(18.00)\end{array}$ & $\begin{array}{l}91(76.50) \\
105(82.00)\end{array}$ & 1.16 & 0.18 & $\begin{array}{l}22(18.50) \\
12(9.40)\end{array}$ & $\begin{array}{l}97(81.50) \\
116(90.60)\end{array}$ & 4.31 & 0.03 \\
\hline $\begin{array}{l}\text { Family support } \\
\text { Supported(199) } \\
\text { Partially supported(48) }\end{array}$ & $\begin{array}{l}14(7.00) \\
8(16.70)\end{array}$ & $\begin{array}{l}185(93.00) \\
40(83.30)\end{array}$ & 4.42 & 0.04 & $\begin{array}{l}26(13.10) \\
8(16.70)\end{array}$ & $\begin{array}{l}173(86.90) \\
40(83.30)\end{array}$ & 0.42 & 0.33 \\
\hline $\begin{array}{l}\text { Marital relationship } \\
\text { Harmony(168) } \\
\text { Not bad(79) }\end{array}$ & $\begin{array}{l}31(18.50) \\
20(21.70)\end{array}$ & $\begin{array}{l}137(81.50) \\
59(78.30)\end{array}$ & 0.47 & 0.30 & $\begin{array}{l}2 I(\mid 2.50) \\
13(16.50)\end{array}$ & $\begin{array}{l}\mid 47(87.50) \\
66(83.50)\end{array}$ & 0.71 & 0.23 \\
\hline
\end{tabular}




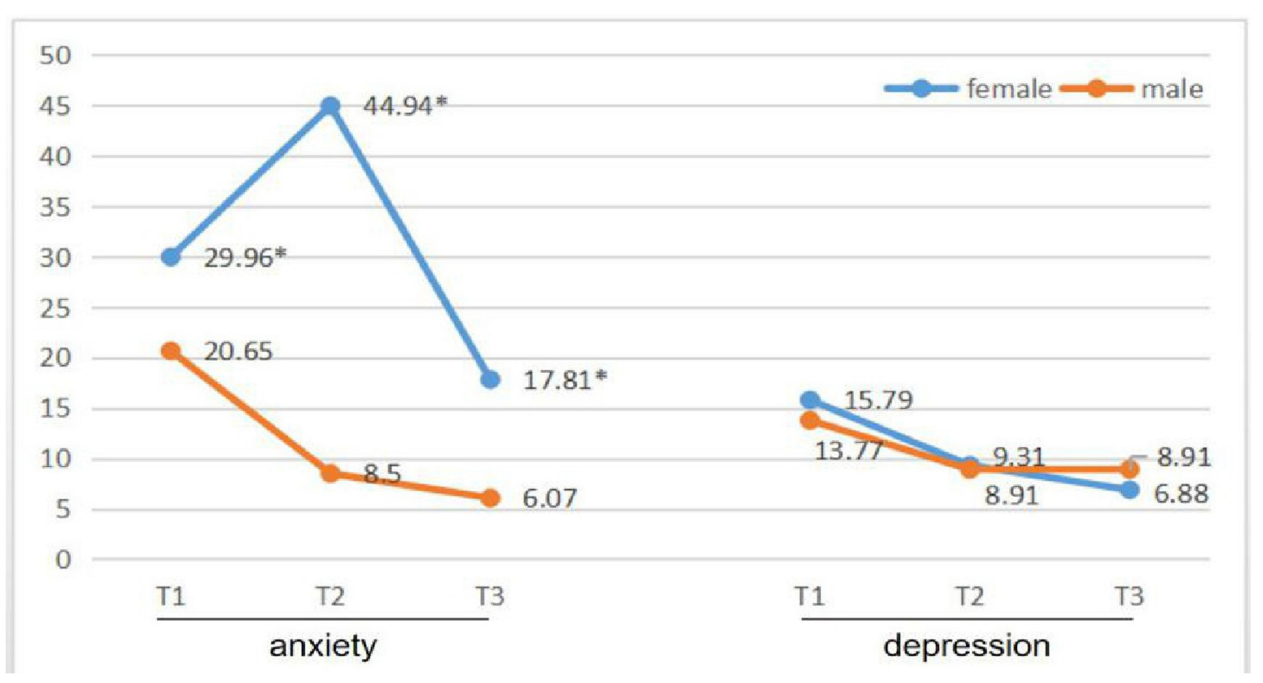

Figure 2 Comparison of the incidence of anxiety and depression in different stages of IVF-ET between women and men. *p $<0.05$ vs men.

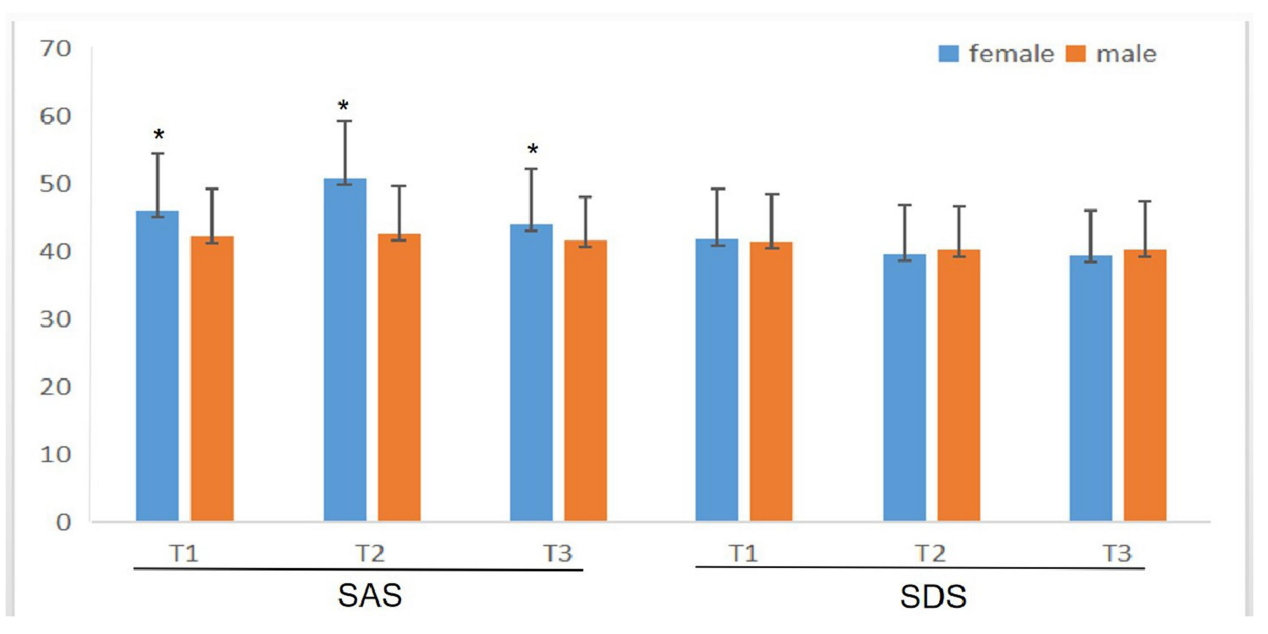

Figure 3 Comparison of the score of anxiety and depression in different stages of IVF-ET between women and men. ${ }^{*} \mathrm{p}<0.05$ vs men.

depression in men undergoing IVF-ET was $20.65 \%$ and $13.77 \%$, respectively, and it was $43.50 \%$ and $29.00 \%$, respectively, in men with primary infertility, which was significantly higher than in men with secondary infertility. However, the findings in men with male infertile factors were $48.90 \%$ and $34.00 \%$, respectively, which were significantly higher than those in men with other infertile factors. The occurrence of anxiety and depression in men with primary infertility or male infertile factors was higher, which may be linked to the increase in male frustration, particularly the influence of Chinese traditional ideals of success, which increases the psychological burden.

It is generally considered that women are more vulnerable to infertility than men. ${ }^{12,14,15}$ Therefore, women will experience higher levels of anxiety and panic when the cause of infertility is only female factors, which may be related to feelings of guilt. ${ }^{16}$ In this study, the incidence and score of anxiety in the three stages were significantly higher in women than in men, while the incidence and score of depression were similar, showing that the anxiety of women is generally higher than that of men during the whole IVF-ET course. Consequently, particular attention should be paid to psychological counseling for infertile women. ${ }^{17}$

Infertile couples experience different problems or confusion in the diverse stages of IVF-ET. ${ }^{18,19}$ Before entering the cycle, they are under pressure due to the history of infertility. Although IVF-ET will bring hope to them, the success rate is not $100 \%$, which means the treatment 


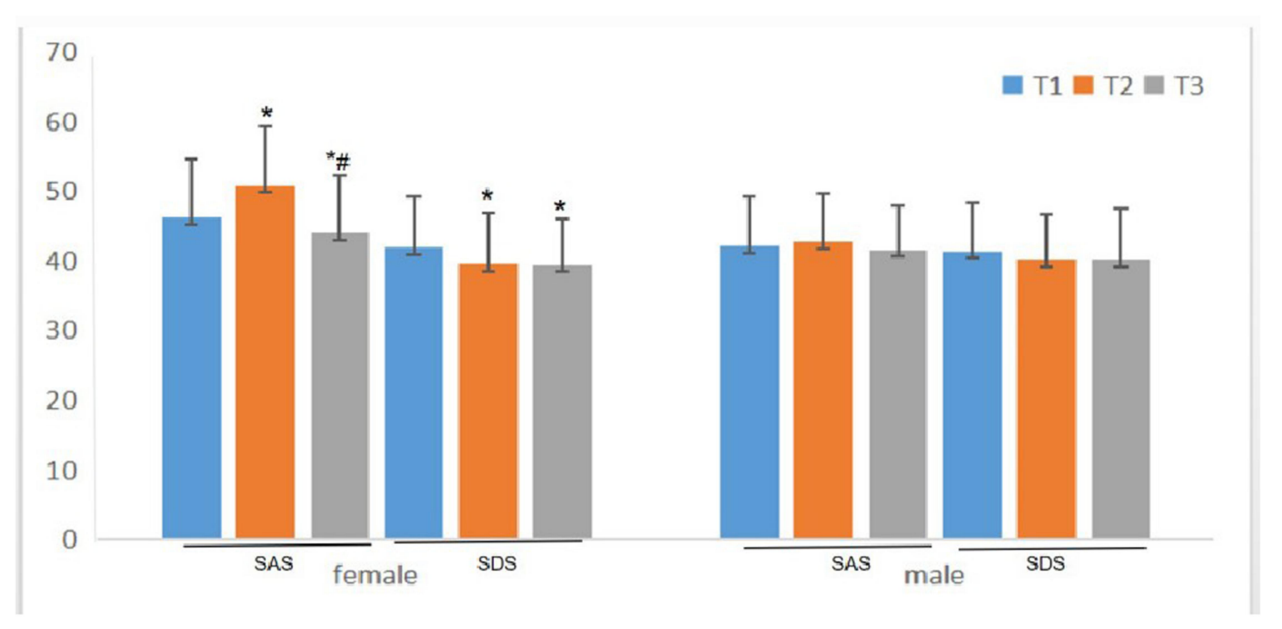

Figure 4 Changes in anxiety and depression scores in different stages of IVF-ET in women/men. The anxiety score in the T2 stage was the highest in women, and it was significantly higher than that in stages TI and T3. The depression score of women in the TI stage was the highest, and it was significantly higher than in stages T2 and T3. * $<0.05$ vs TI; ${ }^{\#} \mathrm{P}<0.05$ vs T2.

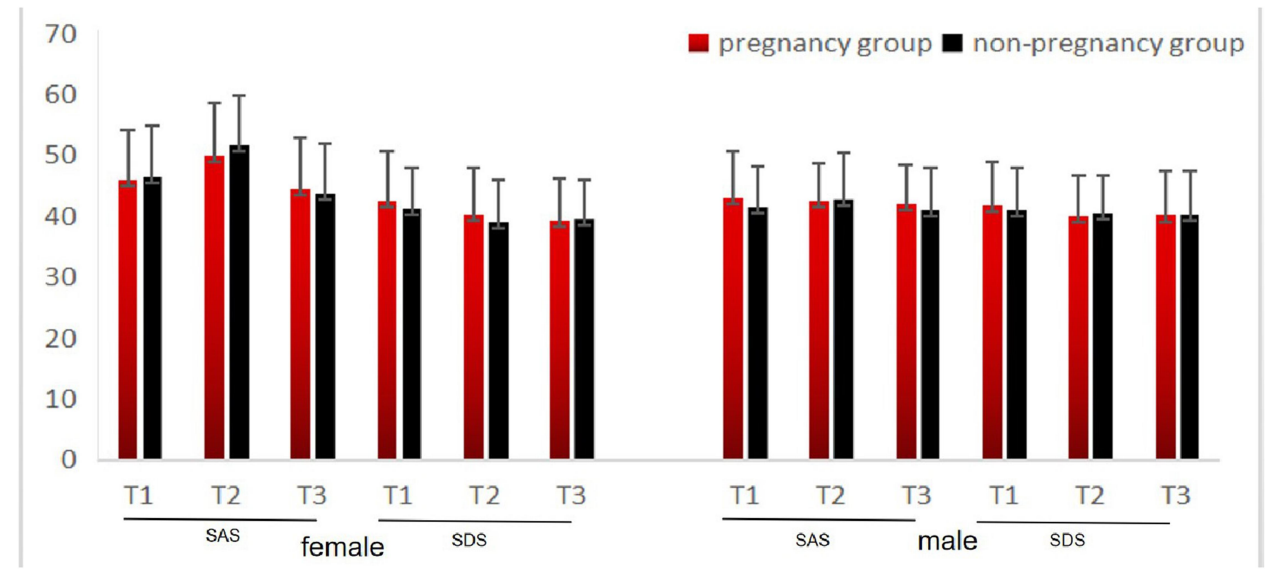

Figure $\mathbf{5}$ Comparison of anxiety and depression scores in different IVF-ET outcomes.

effect is uncertain, and therefore there is a psychological burden. ${ }^{20,21}$ On the day hCG is administered, there are higher expectations of success, abdominal distension due to ovarian growth (particularly in those at high risk of OHSS), and the fear of egg retrieval surgery (particularly during the operation without general anesthesia that will increase the patients' fear of pain and cause nervousness). After embryo-transfer, the patients are concerned about the time, money, whether the psychological efforts will have good results, and what to do if they fail. ${ }^{20}$ This study compared the changes in anxiety and depression in diverse stages in women/men undergoing IVF-ET. The results showed that the anxiety score of women was the highest on the day of hCG administration and the depression score was the highest on the day of entering the cycle, which was significantly higher than that in the other two stages. There was no significant difference in the anxiety and depression scores in men between the different periods. Awtani et al found that women receiving IVF-ET were most anxious after embryo-transfer, ${ }^{20}$ whereas in this study, women had the highest anxiety score on the day of hCG administration, which may be related to the lack of general anesthesia that increases the patients' fear of pain during surgery. Furthermore, the correlation analysis was feasible in avoiding this effect. The depression score reduced after starting the IVF-ET course, showing that active treatment could improve the depressive state of infertile women.

The influence of the infertile couples' psychological status on the IVF-ET outcome is a concern. This study 
found that there were no significant differences in anxiety and depression scores between the different IVF-ET outcomes, as reported by Maroufizadeh et al. ${ }^{22,23}$ These results indicate that anxiety and depression in infertile couples may not affect the IVF-ET outcome. However, in infertile women that experience failure in IVF-ET treatment, depression and anxiety are higher and lead to low quality of life. ${ }^{6,24}$ Therefore, psychosocial intervention and support should be provided effectively to reduce the psychological distress in these women.

\section{Limitations}

This study has some limitations, however, for example, the sample size is not large enough. Larger studies, preferably in the form of randomized controlled trials, may be conducted in future research.

\section{Conclusions}

The incidence of anxiety and depression in infertile couples undergoing IVF-ET is higher, particularly in women, and it is related to many factors. More attention should be paid to the psychological state of patients, and appropriate intervention should be provided. According to this study, women are more prone to anxiety and depression throughout IVF-ET, and therefore more attention is needed. However, our study shows that anxiety and depression are not significantly correlated with the outcome of IVF-ET.

\section{Data Sharing Statement}

We declared that materials described in the manuscript, including all relevant raw data, will be freely available to any scientist wishing to use them for non-commercial purposes, without breaching participant confidentiality.

\section{Ethics Approval and Consent to Participate}

This study was conducted with approval from the Ethics Committee of The Affiliated Hospital of Southwest Medical University. This study was conducted in accordance with the Declaration of Helsinki. Written informed consent was obtained from all participants.

\section{Consent for Publication}

All participants signed a document of informed consent.

\section{Acknowledgments}

We would like to acknowledge the hard and dedicated work of all the staff that implemented the intervention and evaluation components of the study.

\section{Funding}

This study was supported in part through a grant from the Luzhou-Southwest Medical University Union Program (2015YJ013) and the Doctoral Research Initiation Fund of the Affiliated Hospital of Southwest Medical University (19084).

\section{Disclosure}

The authors declare that they have no competing interests.

\section{References}

1. Beukers F, Houtzager BA, Paap MC, et al. Psychological distress and anxiety after a successful IVF/ICSI procedure with and without preimplantation genetic screening: follow-up of a randomised controlled trial. Early Hum Dev. 2012;88(9):725-730. doi:10.1016/j. earlhumdev.2012.03.001

2. LoGiudice JA, Massaro J. The impact of complementary therapies on psychosocial factors in women undergoing in vitro fertilization (IVF): a systematic literature review. Appl Nurs Res. 2018;39:220-228. doi:10.1016/j.apnr.2017.11.025

3. Haimovici F, Anderson JL, Bates GW, et al. Stress, anxiety, and depression of both partners in infertile couples are associated with cytokine levels and adverse IVF outcome. Am J Reprod Immunol. 2018;79(4):e12832. doi:10.1111/aji.12832

4. Zung WW. A rating instrument for anxiety disorders. Psychosomatics. 1971;12(6):371-379. doi:10.1016/S0033-3182(71) 71479-0

5. Zung WW. A self-rating depression scale. Arch Gen Psychiatry. 1965;12(1):63-70. doi:10.1001/archpsyc.1965.01720310065008

6. Omani-Samani R, Ghaheri A, Navid B, Sepidarkish M, Maroufizadeh S. Prevalence of generalized anxiety disorder and its related factors among infertile patients in Iran: a cross-sectional study. Health Qual Life Outcomes. 2018;16(1):129. doi:10.1186/s12955-018-0956-1

7. Omani-Samani R, Maroufizadeh S, Almasi-Hashiani A, Amini P. Prevalence of depression and its determinant factors among infertile patients in Iran based on the PHQ-9. Middle East Fertil Soc J. 2018;23(4):460-463. doi:10.1016/j.mefs.2018.03.002

8. Huang LH, Kuo CP, Lu YC, Lee MS, Lee SH. Association of emotional distress and quality of sleep among women receiving in-vitro fertilization treatment.Taiwan. J Obstet Gynecol. 2019;58 (1):168-172.

9. Chen D, Zhang JP, Jiang L, et al. Factors that influence in vitro fertilization treatment outcomes of Chinese men: a cross-sectional study. Appl Nurs Res. 2016;32:222-226. doi:10.1016/j.apnr.2016.07.003

10. Xu H, Ouyang N, Li R, Tuo P, Mai M, Wang W. The effects of anxiety and depression on in vitro fertilisation outcomes of infertile Chinese. Women Psychol Health Med. 2017;22(1):37-43. doi:10.1080/13548506.2016.1218031

11. Chiaffarino F, Baldini MP, Scarduelli C, et al. Prevalence and incidence of depressive and anxious symptoms in couples undergoing assisted reproductive treatment in an Italian infertility department. Eur. J Obstet Gynecol Reprod Biol. 2011;158(2):235-241.

12. Karimzadeh M, Salsabili N, Akbari Asbagh F, Teymouri R, Pourmand G, SoleimaniehNaeini T. Psychological disorders among iranian infertile couples undergoing assisted reproductive technology (ART). Iran J Public Health. 2017;46(3):333-341. 
13. Crawford NM, Hoff HS, Mersereau JE. Infertile women who screen positive for depression are less likely to initiate fertility treatments. HumReprod. 2017;32(3):582-587.

14. Maroufizadeh S, Hosseini M, Rahimi Foroushani A, Omani-Samani $\mathrm{R}$, Amini P. The effect of depression on quality of life in infertile couples: an actor-partner interdependence model approach. Health Qual Life Outcomes. 2018;16(1):73. doi:10.1186/s12955-018-0904-0

15. Maroufizadeh S, Hosseini M, Rahimi Foroushani A, Omani-Saman R, Amini P. Application of the dyadic data analysis in behavioral medicine research: marital satisfaction and anxiety in infertile couples. BMC Med Res Methodol. 2018;18(1):117. doi:10.1186/ s12874-018-0582-y

16. Massarotti C, Gentile G, Ferreccio C, Scaruffi P, Remorgida V, Anserini P. Impact of infertility and infertility treatments on quality of life and levels of anxiety and depression in women undergoing in vitro fertilization. Gynecol Endocrinol. 2019;35(6):485-489. doi:10.1080/09513590.2018.1540575

17. Lim GS, Kayanoth RK, Broekman BF, Chee CY. Perception of a single-session pre-in vitro fertilisation counselling service and attitudes towards support group: a survey of patients in Singapore. Singapore Med J. 2018;59(6):316-321. doi:10.11622/smedj.2017076

18. Ying L, Wu LH, Loke AY. The effects of psychosocial interventions on the mental health, pregnancy rates, and marital function of infertile couples undergoing in vitro fertilization: a systematic review. J Assist Reprod Genet. 2016;33(6):689-701. doi:10.1007/s10815016-0690-8
19. Sultan S, Tahir A. Psychological consequences of infertility. Hellenic J Psychol. 2011;8:229.

20. Awtani M, Kapoor GK, Kaur P, Saha J, Crasta D, Banker M. Anxiety and stress at different stages of treatment in women undergoing in vitro fertilization-intracytoplasmic sperm injection. J Hum Reprod Sci. 2019;12(1):47-52. doi:10.4103/jhrs.JHRS 2318

21. Ishihara $\mathrm{O}$, Adamson GD, Dyer $\mathrm{S}$, et al. International committee for monitoring assisted reproductive technologies: world report on assisted reproductive technologies, 2007. Fertil Steril. 2015;103 (2):402-413.e11. doi:10.1016/j.fertnstert.2014.11.004

22. Maroufizadeh S, Omani-Samani R, Bagheri-Lankarani N, AlmasiHashiani A, Amini P. Factors associated with poor well-being of infertile people: a cross-sectional study. Middle East Fertil Soc J. 2018;23(4):468-470.

23. Boivin J, Griffiths E, Venetis CA. Emotional distress in infertile women and failure of assisted reproductive technologies: meta-analysis of prospective psychosocial studies. BMJ. 2011;342: d223. doi:10.1136/bmj.d223

24. Lintsen AM, Verhaak CM, Eijkemans MJ, Smeenk JM, Braat DD. Anxiety and depression have no influence on the cancellation and pregnancy rates of a first IVF or ICSI treatment. Hum Reprod. 2009;24(5):1092-1098. doi:10.1093/humrep/den491
Neuropsychiatric Disease and Treatment

\section{Publish your work in this journal}

Neuropsychiatric Disease and Treatment is an international, peerreviewed journal of clinical therapeutics and pharmacology focusing on concise rapid reporting of clinical or pre-clinical studies on a range of neuropsychiatric and neurological disorders. This journal is indexed on PubMed Central, the 'PsycINFO' database and CAS, and is the official journal of The International Neuropsychiatric Association (INA). The manuscript management system is completely online and includes a very quick and fair peer-review system, which is all easy to use. Visit http://www.dovepress.com/testimonials.php to read real quotes from published authors. 